\title{
Pigmentation Restored in Mutant Laboratory Strain of the Lady Beetle Coleomegilla maculata through Dietary Supplementation
}

\author{
Margaret Louise Allen \\ US Department of Agriculture, Agricultural Research Service, Biological Control of Pests Research Unit, \\ Stoneville, Mississippi, USA \\ Email: meg.allen@ars.usda.gov
}

Received 7 April 2016; accepted 27 June 2016; published 30 June 2016

Copyright (C) 2016 by author and Scientific Research Publishing Inc. This work is licensed under the Creative Commons Attribution International License (CC BY). http://creativecommons.org/licenses/by/4.0/

(c) (i) 0 pen Access

\begin{abstract}
A laboratory colony of Coleomegilla maculata (DeGeer), ye, selected for a pigmentation deficiency, was restored to near wild type cuticle coloration by adding crushed heads and wings of the red colored parental strain to the diet. While the wings and other colored portions of the cuticle regained the red color, the eyes of the pigmentation deficient insects were not changed from the pale mutant form. Plant derived carotenes lycopene and beta-carotene did not restore the mutant beetles to a visibly distinguishable red color. An additional pigmentation deficient mutant strain, gold, partially recovered red cuticle color when provided with diet containing pigmented insect particles. This work represents the first rescue of a color phenotype in a lady beetle.
\end{abstract}

\section{Keywords}

Lady Beetle, Recessive Phenotype, Carotenoid Pigments, Forward Genetics, Mutant Rescue, Dietary Supplement

\section{Introduction}

Many species of lady beetles (Coleoptera: Coccinellidae) are characterized by bright red or yellow coloration, often with dark patterning. The red colors of lady beetles are generally accepted to be carotenoid pigments. The species Coleomegilla maculata (DeGeer) (Coleoptera: Coccinellidae) is commonly called the pink lady beetle or the twelve-spotted lady beetle. C. maculata is a beneficial omnivorous beetle ubiquitous in North American 
agroecosystems. The name "pink lady beetle" describes the typical color hues attributed to C. maculata: dark spots on a lighter background that is pink to red or orange.

A stable homozygous strain of beetles with pale yellow coloration in the cuticle, ye, was selected from specimens collected in Mississippi [1] and established as a robust continuous laboratory colony. The ye strain also had no visibly apparent pigments in the eyes. The mutation resulting in the phenotype was inherited as a single autosomal allele, and other than the distinctive coloration the mutant insect colony was apparently healthy [1]. An additional phenotype appearing nearly as pale in the colored portion of the cuticle, but maintaining dark eye coloration similar to the wild type, was observed and selected for over 30 generations. The second selected stable homozygous strain was named gold [2]. This strain was based on inheritance of two alleles that were both autosomal, and apparently independent of the ye allele. The gold insects were less fit as indicated by smaller size/mass and lower egg production compared to wild type and ye beetles [2]. Establishment of the two distinct genetic strains apparently lacking red pigments as heritable characters suggested that the red color was enzymatically controlled, and that critical steps in the production, packaging, or transport of the red pigment were disrupted by genetic malfunction in the naturally occurring mutant alleles present in the ye and gold strains.

To begin the process of clarifying the nature of the ye and gold mutant strains, I designed experiments incorporating candidate compounds into insect diet. Digital images of the adult mutant insects fed these diets were collected, and digital color signatures of the resulting pigmentation characteristics were analyzed. These rescue experiments are the first efforts of their kind performed using a beetle from the family Coccinellidae.

\section{Methods}

Insects were reared as described previously [3], and maintained in growth chambers set for $14 \mathrm{~h} / 10 \mathrm{~h}$ photophase/scotophase lighting. Temperatures were $24^{\circ} \mathrm{C}$ during photophase and $21^{\circ} \mathrm{C}$ during scotophase. Individuals used for experiments were kept isolated in small dishes $(100 \mathrm{~mm} \mathrm{D} \times 26 \mathrm{~mm} \mathrm{H})$ with fine mesh glued into the lid to permit ventilation. Live pupae were weighed individually using a Sartorius CP2P-F analytical balance, and those with a mass between 15 - $20 \mathrm{mg}$ were used for adult experiments.

Digital images were collected using a Nikon digital camera, DMX 1200, with factory supplied ACT-1 software. The camera was mounted on a Nikon Stereomicroscope SMZ1500 (Nikon Corporation, Tokyo, Japan) with aperture fully closed to provide maximum depth of field. Shutter speeds varied from 1/20 to 1/100 sec depending on magnification. Subjects were illuminated by a high intensity fiber optic illuminator, Nikon model NI-150 with dual gooseneck light guides from two opposing sides to provide consistent color readings. Specimens were rotated to collect images that could be sampled for color analysis. Sections of cuticle that were neither in shadow nor reflecting from the light source were selected for color analysis. Images used to analyze cuticle color were cropped to include only the pink or yellow sections of the elytra (forewings) and converted to .jpg files then analyzed using RGB software [4]. Four sections of each sampled individual whole insect were used for color analysis, a single insect was considered a replicate for statistical analysis. Color samples were cropped from colored areas between the melanized spots on the elytra.

Experimental diets were prepared from ground bee pollen, Brewers yeast, Ephestia eggs or Lygus eggs, and supplemented with $10 \% \mathrm{w} / \mathrm{v}$ one of the following: lycopene, beta-carotene, riboflavin (vitamin B2), folic acid, or pigmented particles of wild type $C$. maculata mature adults. The concentrations of the dietary supplements were as formulated for human consumption; the lycopene was collected from $30 \mathrm{mg}$ gel caps, the beta-carotene was collected from 15mg gel caps, the riboflavin was crushed 100mg tablets, and the folic acid was crushed 400ug tablets (General Nutrition Center, Pittsburg, PA, USA). Diet without supplementation (standard diet) was used as negative control. In a separate experiment, l-kynurenine (MP Biomedicals, LLC, Solon, OH USA) was incorporated into diet at a concentration of $100 \mu \mathrm{g} / \mathrm{ml}$. Colored cuticle particles were prepared by removing wings and heads from fresh red (wild type) beetles and grinding them with a mortar and pestle. A preliminary experiment using $10 \% \mathrm{w} / \mathrm{v}$ crushed head and wings in the diet restored a visually distinct pink color to ye insects when fed to either larvae or newly eclosed adults. Because this concentration was effective in rescuing the color phenotype, and the preliminary test subjects survived the diet treatment, other diet treatments were supplemented at $10 \% \mathrm{w} / \mathrm{v}$.

Data were analyzed by analysis of variance (ANOVA) using SigmaPlot, version 12 software (SSI, San Jose, CA USA). Without transformation data passed normality testing using Shapiro-Wilk or Kolmogorov-Smirnov methods. The Holm-Sidak method using multiple comparison versus control was used for six diet studies; the 
standard diet without any supplementation fed to ye strain insects was used as the control group. For the experiment testing rescue of the gold strain, the Holm-Sidak multiple comparison was implemented without specifying a control group (all pairwise).

\section{Results}

Based on the hypothesis that the ye phenotype was derived from lack of a specific pink pigment, a diet including the pigment should result in restoration of the pink (wild type) color. If, on the other hand, the phenotype was due to lack of a pigment precursor in the laboratory diet, providing sufficient precursor in the diet should restore the color. In a preliminary pilot experiment, particles of wild type (wt) insect wings and heads, the red colored parts of the adult insects, were incorporated into insect diet, and fed to ye larvae. When the larvae metamorphosed into adults, the colored portions of the cuticle were visibly pink. In a second pilot experiment, kynurenine was incorporated into diet fed to ye larvae, resulting in no visually apparent change in phenotype (data not shown). Controlled experiments were performed incorporating readily available dietary supplements, including carotenoid compounds, into insect diet, and providing that diet to insects either after adult eclosion or throughout the juvenile stages. Negative control was a standard diet fed to ye insects, and positive control was the diet incorporating wt red insect particles (rescue diet) fed to ye insects. Visual examination confirmed that a pink color was recovered from the rescue diet in both feeding experiments. The empirically visible characteristics were supported by color analysis. Digital images of representative specimens of the experimental insects, ye strain provided with the six diets after adult eclosion, are shown in Figure 1. The adults are aged 25 days post imaginal ecdysis. The experimental pigmentation, ranging from pale to dark yellow or pink in the case of the adults fed the rescue diet is shown diagrammatically, with a diagrammatic representation of the wild type red color included for reference. As shown in Table 1, digital color analyses further clarified that red $(\mathrm{t}=6.276, p<$ $0.001)$ and green $(t=7.163, p<0.001)$ color components in the group fed rescue diet were significantly different from control in the experiment using adults (Holm-Sidak method using multiple comparison versus control, $\mathrm{df}=5$; standard diet without any supplementation was used as control group). In the experiment using juveniles, all color components in the group fed rescue diet were significantly different from the ye control specimens fed a standard diet: red $(\mathrm{t}=10.797, p<0.001)$, green $(\mathrm{t}=8.778, p<0.001)$, and blue $(\mathrm{t}=5.418, p<0.001)$. Specimens fed diet supplemented with plant derived carotenes, lycopene and $\beta$-carotene, did not recover a pink color
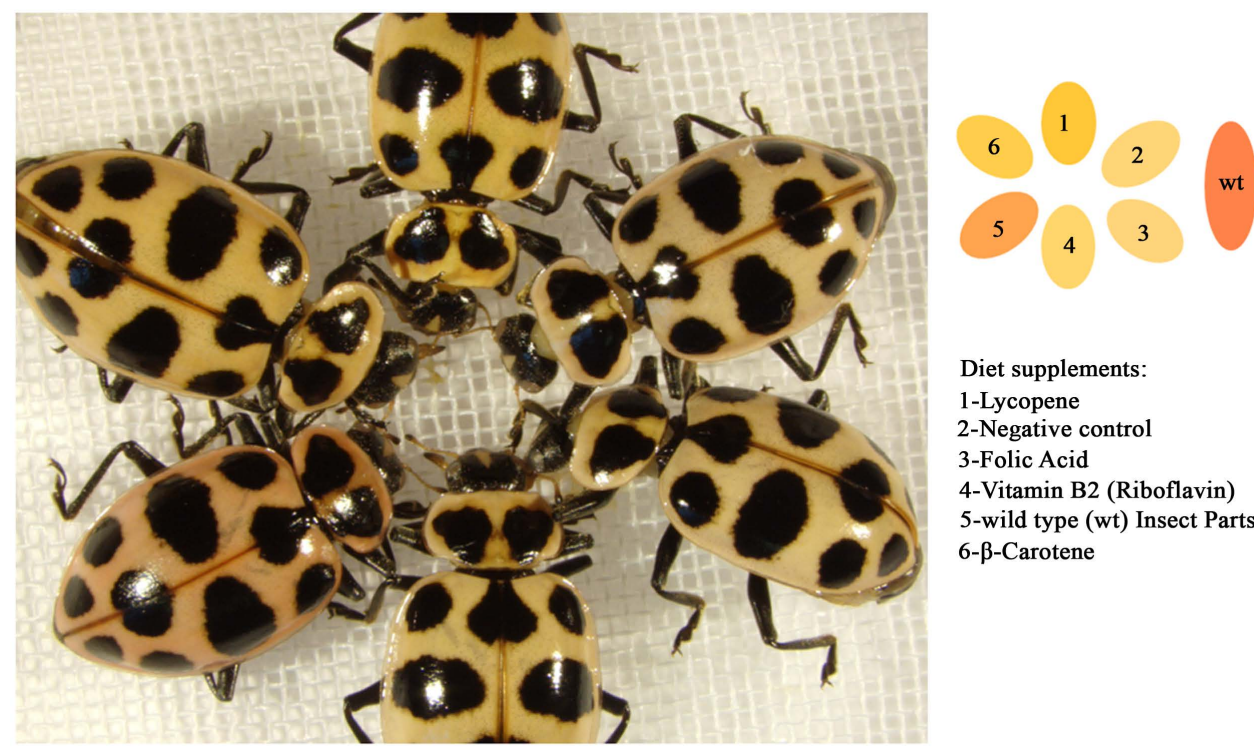

Diet supplements:

1-Lycopene

2-Negative control

3-Folic Acid

4-Vitamin B2 (Riboflavin)

5-wild type (wt) Insect Parts

6- $\beta$-Carotene

Figure 1. Representative specimens of the yellow (ye) strain of Coleomegilla maculata fed diet supplemented with five materials, an unsupplemented diet (negative control). Specimens were fed experimental diets immediately and continuously after adult eclosion (aae); image was collected 25 days (aae). Legend to the right shows the numbering of the specimens arranges as in the image, with color backgrounds matching the color percentages of the samples as measured, and adjusted to color saturation. The ellipse to the right labeled wt represents the average saturated color of the wild type (wt) strain. 
Table 1. Color components (red, green, blue) of colored samples of elytra from specimens of Coleomegilla maculata, strain ye, provided with supplemented diets. An asterisk (*) indicates significantly different from control. Values are percentages plus or minus standard error.

\begin{tabular}{cccccccccc}
\hline & \multicolumn{4}{c}{ Fed rescue diet after adult emergence } & & \multicolumn{3}{c}{ Fed rescue diet after egg hatch } \\
\hline Supplement & Percent red & Percent green & Percent blue & $\begin{array}{c}\text { Sample } \\
\text { size }\end{array}$ & Percent red & Percent green & Percent blue & $\begin{array}{c}\text { Sample } \\
\text { size }\end{array}$ \\
\hline Control & $43.114 \pm 0.491$ & $35.657 \pm 0.109$ & $21.243 \pm 0.483$ & 7 & $43.350 \pm 0.406$ & $36.300 \pm 0.087$ & $20.333 \pm 0.485$ & 12 \\
Folic Acid & $42.757 \pm 0.285$ & $35.957 \pm 0.102$ & $21.286 \pm 0.360$ & 7 & $43.167 \pm 0.426$ & $36.044 \pm 0.128$ & $20.789 \pm 0.519$ & 9 \\
Riboflavin & $43.400 \pm 0.586$ & $36.300 \pm 0.156$ & $20.314 \pm 0.707$ & 7 & $44.171 \pm 0.814$ & $37.114 \pm 0.243^{*}$ & $18.700 \pm 1.056$ & 7 \\
Lycopene & $46.586 \pm 0.280^{*}$ & $36.671 \pm 0.278^{*}$ & $16.771 \pm 0.403^{*}$ & 7 & $50.063 \pm 0.544^{*}$ & $38.9975 \pm 0.208^{*}$ & $10.925 \pm 0.692^{*}$ & 8 \\
$\beta$-Carotene & $45.300 \pm 0.575^{*}$ & $36.571 \pm 0.274^{*}$ & $18.143 \pm 0.792^{*}$ & 7 & $47.555 \pm 0.589^{*}$ & $38.391 \pm 0.277^{*}$ & $14.055 \pm 0.715^{*}$ & 11 \\
WT elytra & $46.543 \pm 0.690^{*}$ & $33.714 \pm 0.191^{*}$ & $19.757 \pm 0.528$ & 7 & $51.245 \pm 0.619^{*}$ & $33.000 \pm 0.197^{*}$ & $15.736 \pm 0.561^{*}$ & 11 \\
\hline
\end{tabular}

by visual inspection, but did appear deeper yellow (Figure 1). Color components were significantly different (Table 1). Adult insects fed diet supplemented with $\beta$-carotene had significantly higher red percentage $(\mathrm{t}=$ 3.741, $p=0.003)$, significantly higher green percentage $(\mathrm{t}=3.265, p=0.010)$, and significantly lower blue percentage ( $\mathrm{t}=3.894, p=0.003)$, while insects fed the $\beta$-carotene diet as juveniles had significantly different color values in all components: red $(\mathrm{t}=5.750, p<0.001)$, green $(\mathrm{t}=13.645, p<0.001)$, and blue $(\mathrm{t}=7.401, p<$ 0.001 ). Adult insects fed diet supplemented with lycopene had significantly different color values in all components: red $(\mathrm{t}=6.024, \mathrm{p}<0.001)$, green $(\mathrm{t}=3.344, p=0.011)$, and blue $(\mathrm{t}=5.545, p<0.001)$. Insects fed the lycopene diet as juveniles also had significantly different color values in all components: red $(\mathrm{t}=8.395, p<0.001)$, green $(\mathrm{t}=9.887, p<0.001)$, and blue $(\mathrm{t}=10.142, p<0.001)$. Mutant ye insects fed diet supplemented with riboflavin as juveniles differed significantly in the green color component $(\mathrm{t}=2.867, p=0.019)$, but other color components were not significantly different from the ye control; ye insects fed diet supplemented with riboflavin as adults and those fed diet supplemented with folic acid as both adults and juveniles did not have differences in color $(\mathrm{t}<1.00, p>0.05)$. A diagrammatic representation of the colors exhibited by the ye insects fed supplemented diet throughout their juvenile stages is presented as Figure 2.

An additional experiment comparing rescue using both pigmentation defective strains, ye and gold, is illustrated in Figure 3, and color analysis results are shown in Table 2. The two mutant strain colors did not differ in any of the three color components when fed standard diet, but the colors of the specimens fed the rescue diet differed significantly in all components with the exception of the blue component for the rescued gold strain. All color components, red $(\mathrm{F}=21.101, \mathrm{df}=3, p<0.001)$, green $(\mathrm{F}=97.184, \mathrm{df}=3, p<0.001)$, and blue $(\mathrm{F}=8.305$, $\mathrm{df}=3, p=0.003$ ) varied significantly among the treatment groups.

No restoration of color in the eyes of ye adults was ever visually apparent, and color analyses were not performed. An expanded view of the heads, with eyes indicated by arrows, is provided in Figure 3(b) (ye strain) and Figure 3(c) (gold strain).

\section{Discussion}

Research focusing on insect pigments has provided insight into basic genetics, cell biology, and biochemistry. While most foundational research has utilized the model insect Drosophila melanogaster [5], research on insect carotenoid metabolism has been performed in the silk moth Bombyx mori [6]. While many lady beetles are notable for brilliant red pigmentation, the biochemistry and molecular genetics of these pigments are largely unknown. The red colors of the elytra of the lady beetle Coccinella septempunctata are attributed to numerous forms of carotenoids including lycopene and $\beta$-carotene [7]. The inheritance, biochemistry, and molecular genetics of insect pigmentation have been an active and vital area of study for over a century. Basic genetic inheritance and sex linkage were first demonstrated in D. melanogaster based on eye colors. Since then hundreds of color mutations have been studied in many organisms including humans. By crossing selected mutant strains of D. melanogaster, the functions of specific pigments in the fly photoreceptor system were deduced [8]. The specific steps of the enzymatic pathways resulting in white, red, orange, and brown eye color mutant phenotypes in 


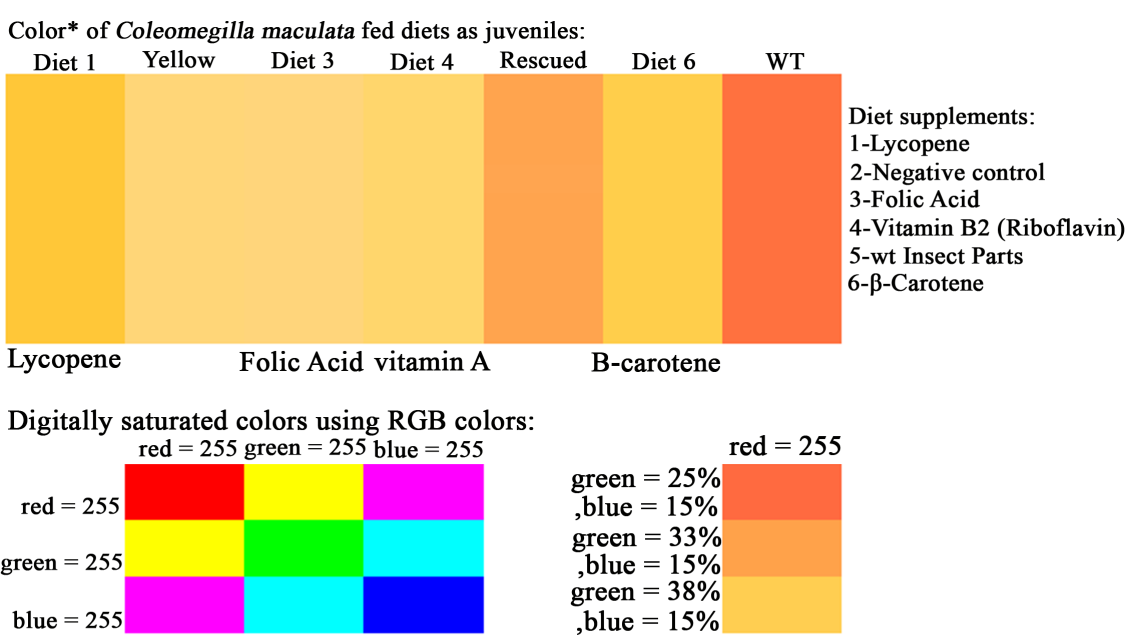

*Colors are calculated based on measured percentages, and then saturated by setting the primary (red) component to full digital color value, 255, and adjusting green and blue components proportionally.

Figure 2. Measured mean colors of ye strain C. maculata fed experimental diets throughout juvenile development, and continued as adults. Color bars are digitally adjusted to saturated color as described in text*. Saturated color bars are provided for comparison below and to the left; samples of colors incorporating scaled green components for comparison are shown below and to the right.

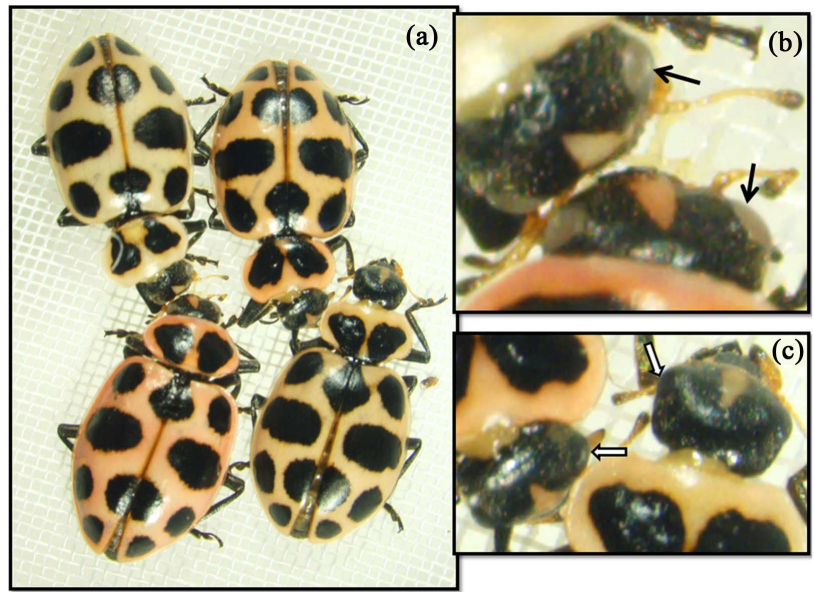

Figure 3. Representative specimens of ye and gold strain C. maculata fed diet supplemented with or without rescue diet that included crushed particles of wild type red pigmented cuticle, primarily elytra and heads. (a) Clockwise from upper left: ye control, gold rescue, gold control, ye rescue; (b) Heads of ye insects, control above, rescue below. Arrows indicate compound eyes lacking pigment; (c) Heads of gold insects, control right, rescue left. Arrows indicate pigmented compound eyes.

Table 2. Color components (red, green, blue) of colored image samples of elytra from specimens of ye and gold strains Coleomegilla maculata provided with standard diet or diet supplemented with particles of wild type red pigmented cuticle (rescue diet). Identical letters indicate values not significantly different; alphabetical order of letters indicates difference from ye standard diet value. Values are percentages plus or minus standard error.

\begin{tabular}{ccccc}
\hline Treatment (strain diet) & Percent red & Percent green & Percent blue & Sample size \\
\hline ye standard & $36.475 \pm 0.525 \mathrm{~A}$ & $35.100 \pm 0.041 \mathrm{a}$ & $28.450 \pm 0.548 \mathrm{a}$ & 4 \\
gold standard & $38.100 \pm 0.196 \mathrm{AB}$ & $34.750 \pm 0.065 \mathrm{a}$ & $27.125 \pm 0.266 \mathrm{a}$ & 4 \\
ye rescue & $42.325 \pm 0.461 \mathrm{C}$ & $32.575 \pm 0.131 \mathrm{c}$ & $25.100 \pm 0.739 \mathrm{~b}$ & 4 \\
gold rescue & $39.700 \pm 0.807 \mathrm{~B}$ & $33.875 \pm 0.170 \mathrm{~b}$ & $26.400 \pm 0.660 \mathrm{ab}$ & 4 \\
\hline
\end{tabular}


D. melanogaster have been characterized biochemically [9] and through molecular genetic methods [10]. Many steps of the biochemical synthesis pathways for pigments in many other insects have been identified, and more are being found and characterized regularly. For example, a mutant strain of the silk moth Bombyx mori characterized by abnormal pigmentation in the eyes and eggs was used to identify a novel function of a major facilitator transporter gene thought to catalyze a terminal step in pigment biosynthesis [11]. A robust transcriptome analysis of two colorful spiders provided a fundamental set of pigment related genes in non-insect arthropods [12].

Insect pigments may be categorized chemically as ommochromes or pteridines, which are usually associated with eye color; melanins which are associated with dark or black cuticle; and carotenes in some lady beetle wings [7]. In the beetle genetic model organism Tribolium castaneum, several pigment genes that are orthologs to characterized $D$. melanogaster genes have been identified, including eye color pigments that result in red or loss of red in the mutant fly phenotype [13]. Interestingly, loss of function experiments in beetles using genes encoding tryptophan-to-ommochrome pathway enzymes resulted in white eyed beetles [14]. Further studies using ATP-binding cassette (ABC) transmembrane transporter genes in T. castaneum also resulted in loss of eye pigments rather than red or pink eyes, supporting the conclusion that eye pigments in this beetle were composed only of ommochromes [13]. Enzymes resulting in cuticle darkening and hardening have been characterized in $T$. castaneum, and a black beetle phenotype similar to the spontaneous mutant strain ebony was produced by gene suppression [15].

Phenotype rescue experiments are crucial tools in genetic discovery. In genetic model organisms, rescue is most often performed by providing a protein coding construct that restores a genetic deficiency. For example, the $D$. melanogaster gene encoding the enzyme kunurenine hydroxylase, cinnabar ( $c n$ ) was injected as a plasmid into a white eyed mutant strain of the mosquito Aedes aegypti, and resulted in partial restoration of eye color. The mosquito eye color was also restored by providing 3-hydroxykynurnine, an ommochrome eye color precursor, to juveniles [16]. A concentration of $100 \mu \mathrm{g} / \mathrm{ml}$ kynurenine preparations was sufficient to rescue eye color in D. melanogaster with null mutations in genes of the ommochrome biosynthetic pathway [16], but this concentration of l-kynurenine did not affect ye mutants when provided in the diet. This suggests that the tryptophan oxygenase gene is probably not responsible for the ye phenotype, and that eye and wing colors in lady beetles may not be ommochrome pigments. Prior to gene sequencing, transplantation of larval eye discs into $D$. melanogaster eye color mutant strains proved the gene to enzyme correlation [17].

The experiments presented here show that the colors diffused throughout the colored portion of the $C$. maculata cuticle can be influenced by diet. The compounds selected as dietary supplements were two plant derived carotenoids, lycopene and $\beta$-carotene, and two B vitamins, riboflavin and folic acid. Lycopene is a red pigment responsible for red colors of fruits and vegetables, and $\beta$-carotene is an orange pigment. Both riboflavin and folic acid are yellow compounds. Carotenoids provided in the form of lycopene and $\beta$-carotene changed the character of the elytra color; the increases in the red and green components of the red/green/blue (rgb) spectrum resulted in a color shift toward more vibrant yellow (Figure 1 and Figure 2). However, only the specific compound provided by particles of red pigment from the wt adult lady beetles restored red to the elytra, characterized by a decreased green component of the rgb spectrum (Table 1 and Table 2, Figures 1-3). Thus the red pigment in the cuticle of $C$. maculata is a compound other than lycopene or $\beta$-carotene. The nature and mechanisms for the synthesis and deposition of the lady beetle pigment are still unknown, but the pigment is clearly able to diffuse to the cuticle but not the eyes.

There is not yet a genetic model species from the family Coccinellidae. Selected laboratory strains with visible phenotypic markers are excellent tools for gene discovery through forward genetics. The ye strain of C. maculata, a distinctly visible phenotype, is well suited for research on novel genes involved in carotenoid biosynthesis pathways. While the gold strain confirmed the rescue results tested in the ye strain, the delicate nature of the gold insects prevented full replication of the diet supplementation studies performed in the ye strain. Sixteen carotenoid compounds have been specifically described from one species of lady beetle, Coccinella septempunctata (http://carotenoiddb.jp/ORGANISMS/Coccinella_septempunctata.html, accessed 25 February 2016) [18], but the identity of many forms remains unknown [12]. Recently, a gene encoding carotene synthesis was identified in the pea aphid [19], and using sequence comparison to that gene a similar gene was discovered in two-spotted spider mite, Tetranychus urticae [20]. The genes encoding the biosynthetic or transport pathway or pathways for coccinellid pigments are completely unknown.

Clearly there is a genetic mechanism in C. maculata that converts a precursor to a unique red pigment that is 
then distributed to the forewings, or elytra, of the adult insect. The form and function of this pigment in the eye remains a compelling unanswered question.

\section{Acknowledgements}

An earlier version of this manuscript was reviewed by Jian Chen, Sandra Allan, and Michael Grodowitz, and the comments and suggestions provided helpful improvement. The author thanks Mary Elizabeth Huddleston, Morgan Holmes, and Joseph Grey Ballenger for technical support and assistance with insect maintenance. The United States Government has the right to retain a non-exclusive, royalty-free license in and to any copyright of this article. This article reports the results of research only. Mention of a commercial or proprietary product does not constitute an endorsement of the product by the United States Department of Agriculture. USDA is an equal opportunity provider and employer.

\section{References}

[1] Allen, M.L. and Ballenger, J.G. (2014) Genetics and Characteristics of a Pigmentation Defective Laboratory Strain of the Lady Beetle, Coleomegilla maculata. Advances in Entomology, 2, 161-166. http://dx.doi.org/10.4236/ae.2014.24024

[2] Allen, M.L. (2016) Gold: A Unique Pigmentation Defective Laboratory Strain of the Lady Beetle. Advances in Entomology, 4, 11-18. http://dx.doi.org/10.4236/ae.2016.41002

[3] Allen, M.L. and Riddick, E.W. (2012) A System for Harvesting Eggs from the Pink-Spotted Lady Beetle. Psyche: A Journal of Entomology, 2012, Article ID: 923653. http://dx.doi.org/10.1155/2012/923653

[4] Byers, J.A. (2006) Analysis of Insect and Plant Colors in Digital Images Using Java Software on the Internet. Annals of the Entomological Society of America, 99, 865-874. http://dx.doi.org/10.1603/0013-8746(2006)99[865:AOIAPC]2.0.CO;2

[5] Lloyd, V., Ramaswami, M. and Kramer, H. (1998) Not Just Pretty Eyes: Drosophila Eye-Colour Mutations and Lysosomal Delivery. Trends in Cell Biology, 8, 257-259. http://dx.doi.org/10.1016/S0962-8924(98)01270-7

[6] Tsuchida, K. and Sakudoh, T. (2015) Recent Progress in Molecular Genetic Studies on the Carotenoid Transport System Using Cocoon-Color Mutants of the Silkworm. Archives of Biochemistry and Biophysics, 572, 151-157. http://dx.doi.org/10.1016/j.abb.2014.12.029

[7] Britton, G., Lockley, W.J., Harriman, G.A. and Godwin, T.W. (1977) Pigmentation of the Ladybird Beetle Coccinella septempunctata by Carotenoids Not of Plant Origin. Nature, 266, 49-50. http://dx.doi.org/10.1038/266049a0

[8] Harris, W.A., Stark, W.S. and Walker, J.A. (1976) Genetic Dissection of the Photoreceptor System in the Compound Eye of Drosophila melanogaster. Journal of Physiology, 256, 415-439. http://dx.doi.org/10.1113/jphysiol.1976.sp011331

[9] Howells, A.J., Summers, K.M. and Ryall, R.L. (1977) Developmental Patterns of 3-Hydroxykynurenine Accumulation in White And Various Other Eye Color Mutants of Drosophila melanogaster. Biochemical Genetics, 15, 1049-1059. http://dx.doi.org/10.1007/BF00484496

[10] Attrill, H., Falls, K., Goodman, J.L., Millburn, G.H., Antonazzo G., Rey, A.J. and Marygold, S.J. (2016) Fly Base: Establishing a Gene Group Resource for Drosophila melanogaster. Nucleic Acids Research, 44, D786-D792. http://dx.doi.org/10.1093/nar/gkv1046

[11] Osanai-Futahashi, M., Tatematsu, K., Yamamoto, K., Narukawa, J., Uchino, K., Kayukawa, T., et al. (2012) Identification of the Bombyx Red Egg Gene Reveals Involvement of a Novel Transporter Family Gene in Late Steps of the Insect Ommochrome Biosynthesis Pathway. Journal of Biological Chemistry, 287, 17706-17714. http://dx.doi.org/10.1074/jbc.M111.321331

[12] Croucher, P.J., Brewer, M.S., Winchell, C.J., Oxford, G.S. and Gillespie, R.G. (2013)De novo Characterization of the Gene-Rich Transcriptomes of Two Color-Polymorphic Spiders, Theridion grallator and T. californicum (Araneae: Theridiidae), with Special Reference to Pigment Genes. BMC Genomics, 14, 862. http://dx.doi.org/10.1186/1471-2164-14-862

[13] Grubbs, N., Haas, S., Beeman, R.W. and Lorenzen, M.D. (2015) The ABCs of Eye Color in Tribolium astaneum: Orthologs of the Drosophila White, Scarlet, and Brown Genes. Genetics, 199, 749-759. http://dx.doi.org/10.1534/genetics.114.173971

[14] Lorenzen, M.D., Brown, S.J., Denell, R.E. and Beeman, R.W. (2002) Cloning and Characterization of the Tribolium castaneum Eye-color Genes Encoding Tryptophan Oxygenase and Kynurenine 3-Monooxygenase. Genetics, 160, 225234. 
[15] Arakane, Y., Dixit, R., Begum, K., Park, Y., Specht, C.A., Merzendorfer, H., et al. (2009) Analysis of Functions of the Chitin Deacetylase Gene Family in Tribolium castaneum. Insect Biochemistry and Molecular Biology, 39, 355-365. http://dx.doi.org/10.1016/j.ibmb.2009.02.002

[16] Cornel, A.J., Benedict, M.Q., Rafferty, C.S., Howells, A.J. and Collins, F.H. (1997) Transient Expression of the Drosophila melanogastercinnabar Gene Rescues Eye Color in the White Eye (WE) Strain of Aedes aegypti. Insect Biochemistry and Molecular Biology, 27, 993-997. http://dx.doi.org/10.1016/S0965-1748(97)00084-2

[17] Beadle, G. and Ephrussi, B. (1937) Development of Eye Colors in Drosophila: Diffusible Substances and their Interrelations. Genetics, 22, 76.

[18] Takaichi, S. (2011) Carotenoids in Algae: Distributions, Biosyntheses and Functions. Marine Drugs, 9, 1101-1118. http://dx.doi.org/10.3390/md9061101

[19] Moran, N.A. and Jarvik, T. (2010) Lateral Transfer of Genes from Fungi Underlies Carotenoid Production in Aphids. Science, 328, 624-627. http://dx.doi.org/10.1126/science.1187113

[20] Altincicek, B., Kovacs, J.L. and Gerardo N.M. (2012) Horizontally Transferred Fungal Carotenoid Genes in the Two-Spotted Spider Mite Tetranychus urticae. Biology Letters, 8, 253-257. http://dx.doi.org/10.1098/rsbl.2011.0704

\section{Submit or recommend next manuscript to SCIRP and we will provide best service for you:}

Accepting pre-submission inquiries through Email, Facebook, Linkedin, Twitter, etc A wide selection of journals (inclusive of 9 subjects, more than 200 journals)

Providing a 24-hour high-quality service

User-friendly online submission system

Fair and swift peer-review system

Efficient typesetting and proofreading procedure

Display of the result of downloads and visits, as well as the number of cited articles

Maximum dissemination of your research work

Submit your manuscript at: http://papersubmission.scirp.org/ 